\title{
Offshore Wind Farm Connection with Low Frequency AC Transmission Technology
}

\author{
Nan Qin Student Member, IEEE, Shi You, Zhao Xu, Member, IEEE and Vladislav Akhmatov
}

\begin{abstract}
This paper investigates the feasibility of using the low frequency AC transmission (LFAC) system, e.g. fraction of $50 \mathrm{~Hz}$ or $60 \mathrm{~Hz}$, for connecting the large offshore wind farm to the grid by modelling and simulation. The LFAC system improves the transmission capacity and distance compared to the conventional AC solution at the nominal frequency, e.g. $50 \mathrm{~Hz}$ or $60 \mathrm{~Hz}$. and reduces the investment cost compared to the HVDC solution. It is estimated that the LFAC system is competitive in the transmission distance of about $30-150 \mathrm{~km}$. The simulation model of the wind integration using the LFAC system has been developed, which consists of three parts, the fixed-speed wind turbine representing a wind farm, the transmission line and the frequency converter. Although the transmission capability is greatly improved by the LFAC system, simulation shows it gives negative influences on the wind turbine operation due to the reduced inductive reactance of the grid. Moreover, the harmonics introduced by the frequency converter may require extra filters to be installed in such system.
\end{abstract}

Index Terms - offshore wind farm, fixed-speed wind turbine, cycloconverter, LFAC, FFTS

\section{INTRODUCTION}

$\mathrm{T}$ The electricity production from the renewable sources becomes more attractive in the last decade. Amid available renewable energy conversion technologies, the penetration of wind energy in the grid is increasing rapidly. With the goal of European Union, the wind energy capacity will increase to approximately $20 \%$ of the total energy capacity. Larger wind farms with size from $100 \mathrm{MW}$ to 1000 MW are expected to be constructed in the next decade [1].

Due to the space shortage on land and the better wind energy resource, more offshore wind farms like the Horns Rev, with a $160 \mathrm{MW}$ capacity locating about $20 \mathrm{~km}$ out of the west coast of Denmark and about $50 \mathrm{~km}$ to the nearest on-land point of connection [2], are under construction. The trend is that future offshore farms are to be built at farther distance and have a larger installation capacity. From a technical point of view, it is a great challenge to integrate such amount of wind power into the current power system. One of the main issues is the transmission system, linking between the offshore wind farm and the on-land electrical grid, which transmits large amount of power over a long distance. Currently, the possible solutions are: HVAC, Line commutated HVDC and Voltage Source Converter based HVDC (VSC-HVDC).

N. Qin, S.You, Z. Xu and Vladislav Akhmatov are with the Centre for Electric Technology, Department of Electrical Engineering, Technical University of Denmark, DK-2800 Kongens Lyngby, Denmark (e-mail: s060914@student.dtu.dk; sy@elektro.dtu.dk; zx@elektro.dtu.dk ).
From the economic point of view, for the short distance (less than $50 \mathrm{~km}$ ), the HVAC system has the advantage of low cost. As the distance gets longer, e.g. $50 \mathrm{~km}$ and above, considering the cable cost that concerning charging and losses, and the terminal cost, the HVAC transmission is no longer cheap but the HVDC is preferred [3]. Therefore the line commutated HVDC connection is proposed for it is a reliable and mature technology. Later, the technology of VSC-HVDC is introduced by replacing thyristors with IGBTs to perform independent control of the active power and the reactive power in addition to the voltage control [1,4,5]. Different products like HVDC Light from ABB and HVDC Plus from Siemens are all based on the VSC-HVDC concept. The VSCHVDC transmission system has been considered to be the most feasible solution for long distance offshore wind farm transmission system to date, for example $200 \mathrm{~km}$. However, expensive converter stations added on both sides of the transmission system, especially for the offshore converter station, increases dramatically the investment cost for such solution [6,7]. This fact limits the competitiveness of the VSCHVDC when it is applied to short and inter-mediate distance connections. Another drawback of HVDC and VSC-HVDC systems is the space charge accumulation of the cable caused by the DC current during the construction period $[6,8,9]$. Besides, corrosion is always a concern for HVDC systems particularly when implemented as submarine cable.

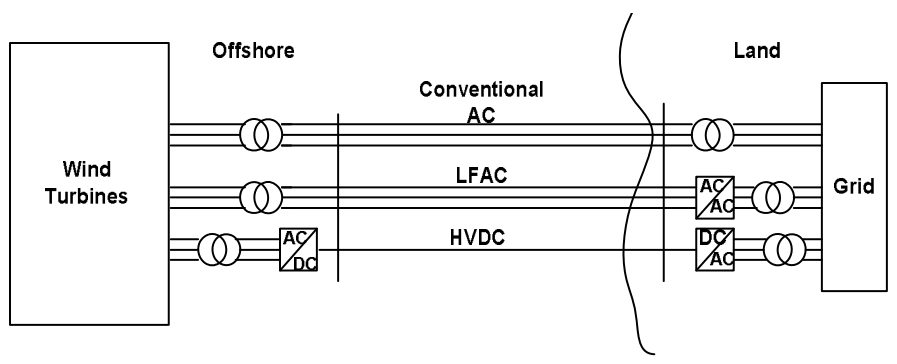

Fig. 1. The layouts of the offshore wind farms transmission systems.

Given the limitations of both the HVAC and HVDC technologies when applied for far offshore wind farm connection, the Low Frequency AC Transmission (LFAC) [10, 11] or Fractional Frequency Transmission System (FFTS) [12] is proposed in this paper as a new and alternative solution. The layouts of the three transmission technologies are shown in Fig. 1. Several advantages are identified for the LFAC system. The transmission capability of the LFAC is greatly improved whereas the cable charging and losses are reduced compared to the traditional HVAC. The investment of the LFAC system is less costly than the VSC-HVDC system in the short and inter-mediate distance, and the subsequent maintenance cost is 
largely reduced as well, since the frequency converter that synchronizes the frequencies between the LFAC system and the main grid AC system can be installed onshore. In fact, a frequency converter can be replaced by a frequency transformer being a tried and tested technology [13]. Other benefits of LFAC system include e.g. improved voltage stability and no space charging accumulation.

This paper focuses on application of the LFAC transmission for connecting an offshore wind farm to the on-land grid. The principle, advantages and disadvantages of the LFAC system will be investigated. The paper is organized as follows: Section II presents the LFAC theory and the structure of the LFAC transmission system. Moreover, a rough economic evaluation for different transmission technologies is included. Section III shows the simulation study, where both the conventional AC and LFAC systems of intermediate length are modelled and simulated for comparisons. In addition, the wind turbine connecting to both systems are presented to verify the feasibility of the LFAC connection. Section IV concludes the paper and provides the further scope.

\section{PRINCIPLE OF THE LFAC CONNECTION}

For AC transmission system, the active power transmitting $(P)$ over the transmission lines, which should be cables for connecting offshore wind farms, can be expressed by:

$$
P=\frac{V_{S} V_{R}}{X} \cdot \sin \delta
$$

where $V_{S}$ and $V_{R}$ are the sending end voltage and the receiving end voltage, respectively. $X$ is the line reactance. $\delta$ is the transmitting angle. Equation (1) is valid when the cable is short that neglects the effect of the line angle [14]. According to Eq.1, for a given transmitting angle, increasing the transmitting power is either by increasing the voltage level or lowering the impedance of the cable. Furthermore, with the fixed sending and receiving end voltages, the only way to improve the transmission capability is by reducing the impedance of the cable.

As the reactance which dominates the line impedance is proportional to the power frequency $f$,

$$
X=2 \pi f L
$$

where $L$ is the total inductance over the line, decreasing the electricity frequency can proportionally increase transmission capability. The LFAC system based on this concept is not only able to increase the transmitting power, but also improve the voltage stability given the same amount of reactive power transmission, as illustrated in Eq. 3 [12].

$$
\Delta V \%=Q X / V^{2} \times 100
$$

where $\Delta V$ is the voltage drop over the cable. $V$ is the nominal voltage. $Q$ is the reactive power flow of the cable. Because the impedance is reduced in the LFAC system due to the lower grid frequency, the voltage drop over the cable is proportionally reduced accordingly. Notice that long AC cables of large offshore wind farms are compensated using shunt reactors, e.g. the cable charging effects are eliminated and disregarded in this presentation.

\section{A. Frequency converter}

The offshore wind farm connection with the LFAC system requires a frequency converter or a variable frequency transformer $[11,12,13]$. Variable frequency transformers are mentioned for completeness of this presentation, but not considered in our work yet. Many papers propose the line commutated cycloconverter for the LFAC system due to its low cost and wide utilization.

Fig. 2 shows a line commutated three-phase/three-phase cycloconverter for transferring $50 \mathrm{~Hz}$ to $50 / 3 \mathrm{~Hz}$ systems is working under the no-load condition. The $50 \mathrm{~Hz}$ voltage source can be taken as the conventional AC grid. The output of each phase is connected to a resistor with an infinite value representing the no-load condition. Each phase requires at least 12 thyristors and the three phases totally need 36 thyristors. The cycloconverter converts $50 \mathrm{~Hz}$ to the lower frequency by firing angle control. By using this frequency converter, it is possible to connect the conventional $50 \mathrm{~Hz}$ system to the LFAC system.

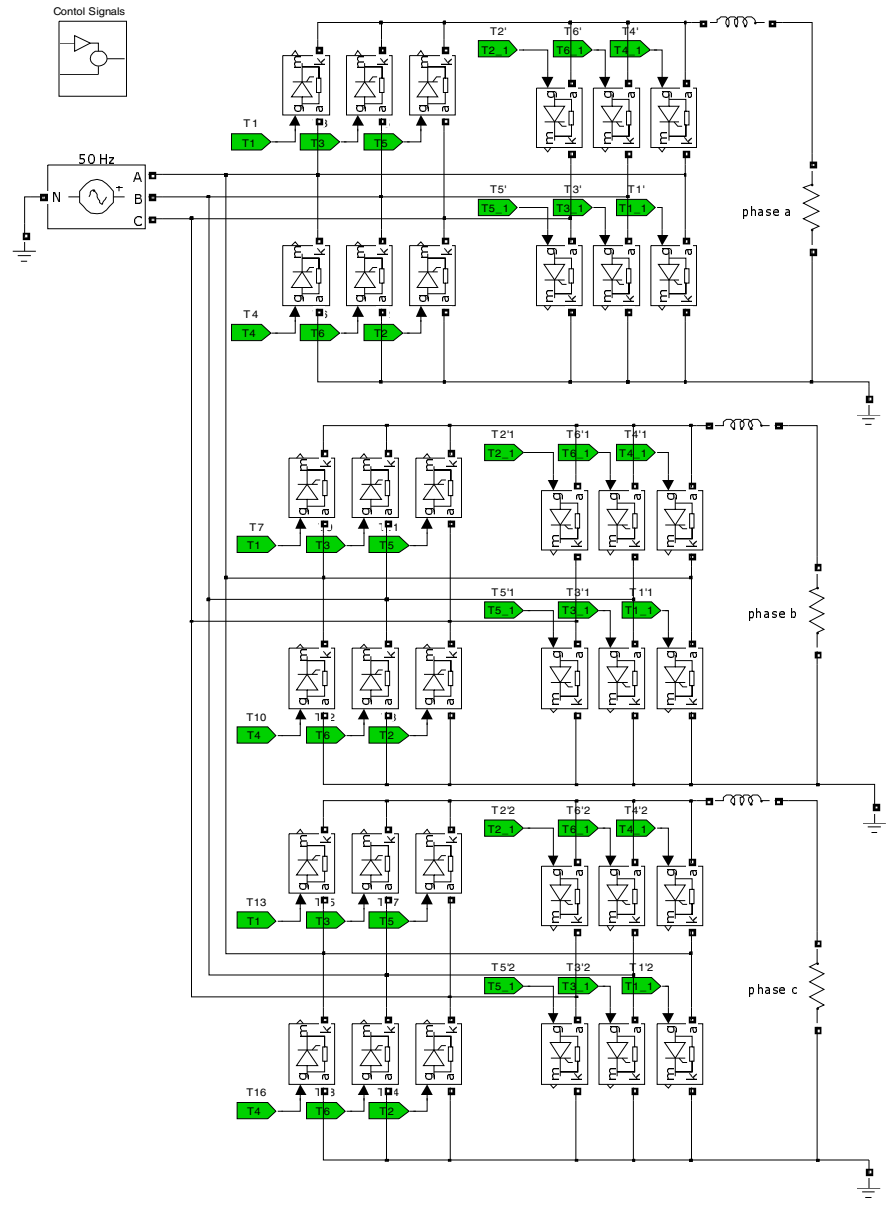

Fig. 2. The line commutated three-phase/three-phase cycloconverter.

\section{B. Frequency range}

The operation frequency of the LFAC system has a range of values that are set by two main factors. One factor is the space charge accumulation of the cables. Experimental results are reported that the space charge accumulation is found when 
imposing $\mathrm{AC}$ frequency lower than $0.1 \mathrm{~Hz}$, but it can be neutralized when the system frequency is higher than $1 \mathrm{~Hz}$. The other factor is harmonics output from the line commutated three-phase/three-phase cycloconverter. The frequency of the LFAC system should be set lower than $1 / 3$ of the conventional nominal frequency to reduce the harmonics, when it is line commutated by the AC line voltages. Therefore, the feasible operation frequency range for $50 \mathrm{~Hz}$ system should be [11]:

$$
0.1 \mathrm{~Hz}<f \leq 50 / 3 \mathrm{~Hz}
$$

In this paper, the $50 / 3 \mathrm{~Hz}$ frequency is used for simulation study to investigate the LFAC system.

\section{Cost comparison}

The investment cost of the transmission system for the offshore connection is mainly comprised of two parts. The terminal cost and the cable cost [3]. As shown in Fig. 1, the conventional AC system has an offshore transformer station and a land substation. The LFAC transmission has one more frequency converter on land comparing with conventional AC system. The VSC-HVDC transmission system needs two more converter stations, one in the sea and the other one on the land. Even though the frequency converter in LFAC system needs at least 36 thyristors, the total terminal cost of the LFAC transmission system is relative lower than the VSC-HVDC system, because the required offshore converter station with transformer and auxiliary equipments in VSC-HVDC system is quite costly. Furthermore, the maintenance cost for equipments offshore is more expensive than if on land.

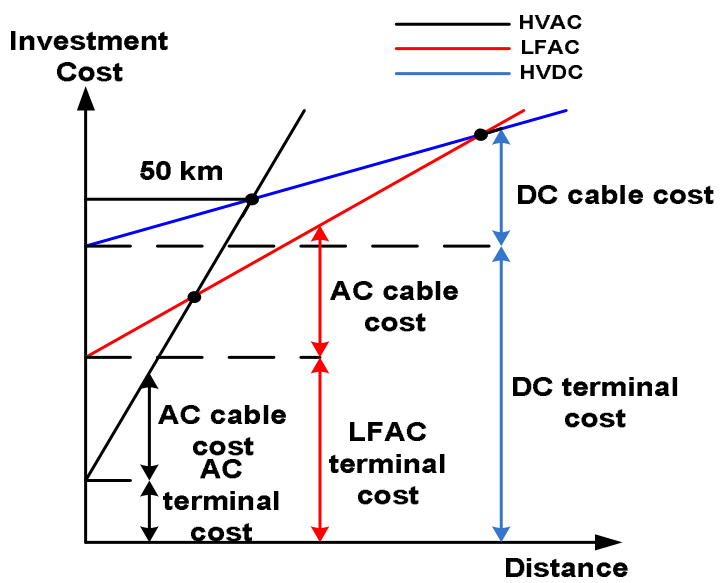

Fig. 3. The investment cost comparison of the three transmission systems.

It is difficult to get the exact value of the total investment cost. But the comparison can be roughly estimated as given in Fig. 3. The crossing points are the so called "break-even distance". The $50 \mathrm{~km}$, which is also the Danish Horn Rev offshore wind farm cable length, is the "break-even distance" of the HVAC and the HVDC transmission systems. The investment cost is lower for the HVAC system than the HVDC system if the distance is shorter than $50 \mathrm{~km}$ and vice verse [3]. If the frequency of the LFAC system is further reduced, the slope of the LFAC curve will reduce. It implies the LFAC solution is much competitive when applying lower frequency. This is a rough comparison. Nevertheless it shows that the LFAC system is a competitive solution when the distance between the offshore wind farm and the on-land gridconnection point is in the range of approximately $30 \mathrm{~km}$ to $150 \mathrm{~km}$. This estimation only takes into account the investment cost. If considering other costs such as for maintenance, LFAC with converter substation onshore can be more competitive in comparison to the HVDC solution.

\section{Simulation OF THE LFAC SYSTEM}

This section studies using LFAC for wind farm grid connection through modelling and simulation. As shown in Fig. 1, possible solutions for offshore wind farm connection can be conventional HVAC connection, the LFAC connection and the HVDC connection. Since HVDC has the disadvantage of higher investment cost for short and intermediate distance transmission, it will not be studied herein. The conventional HVAC transmission system and the LFAC with $50 / 3 \mathrm{~Hz}$ transmission system over intermediate length cable are of particular interest and have be modelled in the Matlab Simulink. The goal of the study is to evaluate the LFAC transmission system for offshore wind farms connection under intermediate or short distance by comparing with the conventional HVAC system.

The simulation model has been separated into three parts: 1). The transmission model 2). Wind turbine model for evaluating the influence on the fixed speed wind turbines connecting to the LFAC system 3). Frequency converter model based on the three-phase/three-phase line commutated cycloconverter.

\section{A. The LFAC transmission}

The models of the 50/3 Hz LFAC transmission and the 50 $\mathrm{Hz}$ conventional AC transmission are shown in Fig. 4. Both ends of each system are the $400 \mathrm{kV}$ voltage sources, but with different frequencies. The cables are model as $\pi$ lines. The series impedance is leakage impedance of the transformers.

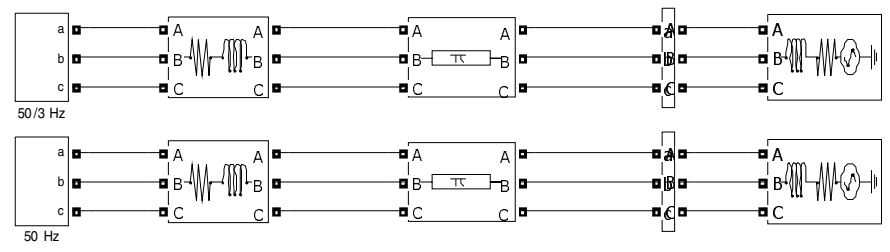

Fig. 4. The conventional $50 \mathrm{~Hz}$ AC transmission system Vs. The LFAC transmission system with 50/3 Hz.

As the Eq. 1 shows, the transmitting power is decided by the transmitting angle when both the sending end voltage and the receiving end voltage are fixed. Varying the transmitting angle from 0 to 180 degree, e.g. in Fig. 5, the transmitting power of the $50 / 3 \mathrm{~Hz}$ system is approximately 3 times of the conventional $50 \mathrm{~Hz} \mathrm{AC}$ system at any transmission angle over e.g. $100 \mathrm{~km}$ length cable.

Using a load with a constant power factor $(0.8 \mathrm{lag})$ to replace the voltage source at the receiving end and increasing the cable length and the transmission angle, the PV curve with no compensation are plotted in Fig. 6. The PV curves of the both 50 and 50/3 Hz systems are moving left when increasing the cable length, meaning that the transmitting power is reduced accordingly. The red line represents the PV curve of the conventional $50 \mathrm{~Hz}$ AC system with the length of $125 \mathrm{~km}$ whilst the solid and the dash blue lines represent the PV curves of the 50/3 Hz LFAC system in the length of $125 \mathrm{~km}$ 
and $375 \mathrm{~km}$, respectively. It is observed that the maximum power transmission occurs at the break point in each system. The $50 / 3 \mathrm{~Hz}$ system can transmit much more power than the conventional $50 \mathrm{~Hz}$ system over the same distance. It also shows smaller deviation from the nominal value than the 50 $\mathrm{Hz}$ system given the same transmission power and distance, indicating the LFAC system requires less reactive power compensation than the conventional AC system. Furthermore, increasing the transmission distance to $375 \mathrm{~km}$, the $50 / 3 \mathrm{~Hz}$ system can still transmit more power with lower voltage drop comparing to the conventional $\mathrm{AC}$ system at the distance of $125 \mathrm{~km}$. This implies the transmission capability of the LFAC system is much better than the conventional AC system.

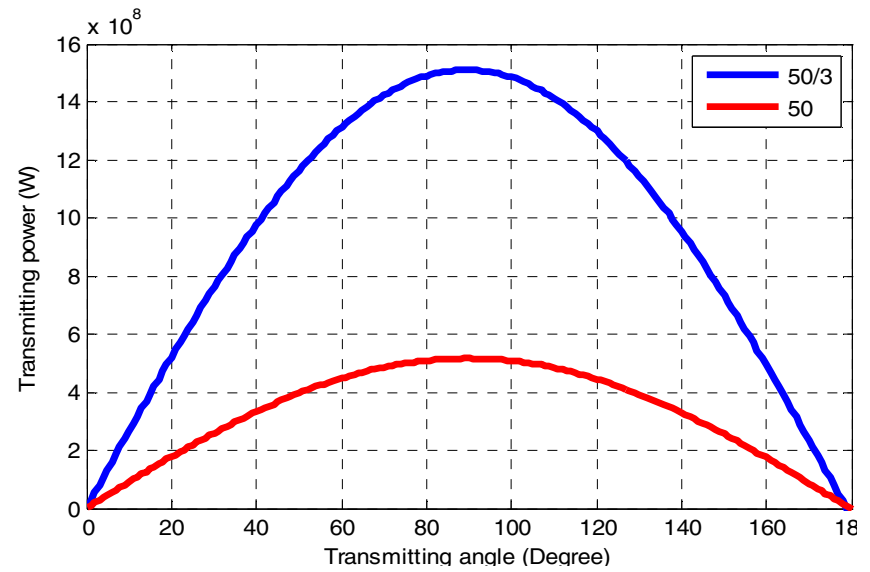

Fig. 5. The transmitting power in different systems with different frequencies.

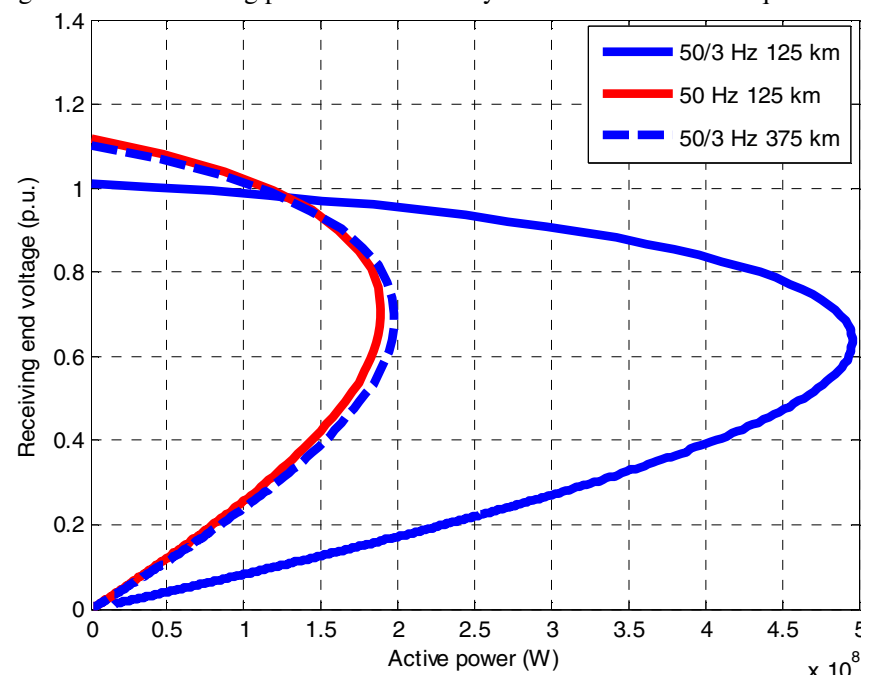

Fig. 6. PV curves of LFAC system and conventional AC system with fixed power factor and varying transmission distances (red: $50 \mathrm{~Hz}$; blue: $50 / 3 \mathrm{~Hz}$ ).

\section{B. Fixed Speed Wind Turbine Based Wind Farm Gird Integration}

The wind turbines generally have 3 types: fixed-speed wind turbines with a capacitor compensator, induction generators with full size back-to-back converters and wind turbines with doubly-fed induction generators. The induction generator with the full-size converter can be integrated to the LFAC system without any difficulty, because the converter isolates the generator from the grid by the DC connection. The grid-side inverter has a Phase Lock Loop (PLL) to synchronize the frequency, for instance, the $50 \mathrm{~Hz}$ or $50 / 3 \mathrm{~Hz}$. The wind turbine with a doubly-fed induction generator has two tracks: the stator connects directly to the grid and the rotor connects to the grid though the partial size converter. The doubly-fed generator is excited by the converter through the rotor circuit. The active power output is controlled according to the wind speed and the control strategy, e.g. the maximum power tracking strategy. Due to the lower grid frequency in the LFAC system, to produce the same amount of power without damage generators may require modified design to the wind turbine system e.g. increased rotating mass and number of poles and winding design for the induction generators.

A fixed-speed wind turbine comprises an induction generator connected to the grid directly without power converter, which usually requires the reactive power compensation from a capacitor bank. Because of no converter, lowering down the frequency can influent fixed-speed wind turbines too much.

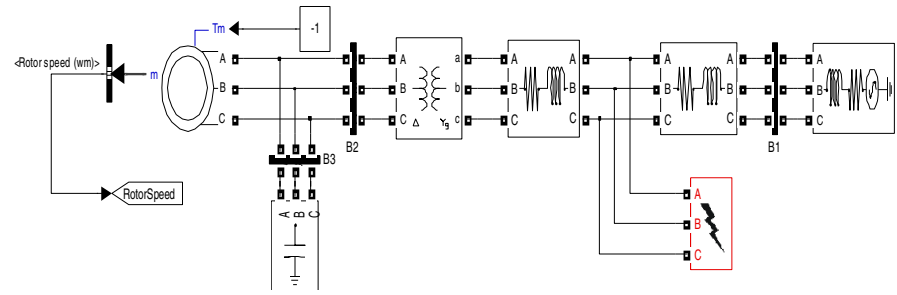

Fig. 7. The topology of fixed-speed generator connected to the utility grid

Fig. 7 shows a fixed-speed wind turbine that connects to the PCC of the wind farm via the transformer and lines. The model is used to investigate the electrical parts of turbine, hence the mechanical parts concerning the rotor blades (and its control), shaft and gear box are not included. These parts have been simplified so that the input to the generator is directly a mechanical torque. Notice that the mechanical power produced by the blades in both cases is the same, because the rotor blades and rotational speed are considered the same regardless from the generator design or operational redesign. This implies that the shaft gear ratio is reduced in case of the low frequency operational regime of the generator. Reduction of the gear box is to be mentioned among advantages of the LFAC design.

In simulating the two cases with different frequencies, the same generator model has been applied. The idea is to, based on the simulation results, analyse and identify the needed redesign for the wind turbine system when the frequency is lowered. When starting up the generator in $50 / 3 \mathrm{~Hz}$ system, the rotor speed of the generator has a huge overshoot and then drops in the steady state with oscillations, as the blue curve shown in the Fig. 8. The dynamicl behavior of the generator can be expressed by

$$
\begin{gathered}
2 H \cdot d \bar{\omega}_{r} / d t=\bar{T}_{m}-\bar{T}_{e} \\
H=J \omega_{0}^{2} / 2 S \\
\bar{\omega}_{r}=\omega_{r} / \omega_{0}
\end{gathered}
$$

where $\bar{T}_{m}$ and $\bar{T}_{e}$ are the input mechanical and generated electromagnetic torques in per unit system, respectively. The mechanical torque is a constant value in the simulation. $\bar{\omega}_{r}$ is the per unit angular velocity based on the actual and rated speeds of $\omega_{r}$ and $\omega_{0}$ respectively. $S$ is the nominal apparent power of the generator, $J$ is the moment of inertia and $H$ is the inertia constant in p.u. system. In Fig. 8, the generator inertia 
$(J)$ is the same for both $50 \mathrm{~Hz}$ and $50 / 3 \mathrm{~Hz}$ cases (blue and black curves). Due to a reduced frequency, the $50 / 3 \mathrm{~Hz}$ system has a reduced $(H)$ that leads to increased oscillation in the starting up process. On the other hand, the $50 / 3 \mathrm{~Hz}$ regime reduces the generated electromagnetic torque that could further contribute to the oscillation. To damp the huge overshoot, increasing of the inertia of the rotating mass is a possible solution. In this paper, the inertia constant $(H)$ in 50/3 $\mathrm{Hz}$ case has been increased to the same level as in the $50 \mathrm{~Hz}$ case, and the red cure in Fig 8 is the resulted simulation, where the oscillation has been largely reduced but still not as good as the original $50 \mathrm{~Hz}$ case. Similar observation is made in Fig 9 for the generator's active power outputs. This indicates another redesign need to optimize the inertia value that can address the oscillation phenomena.

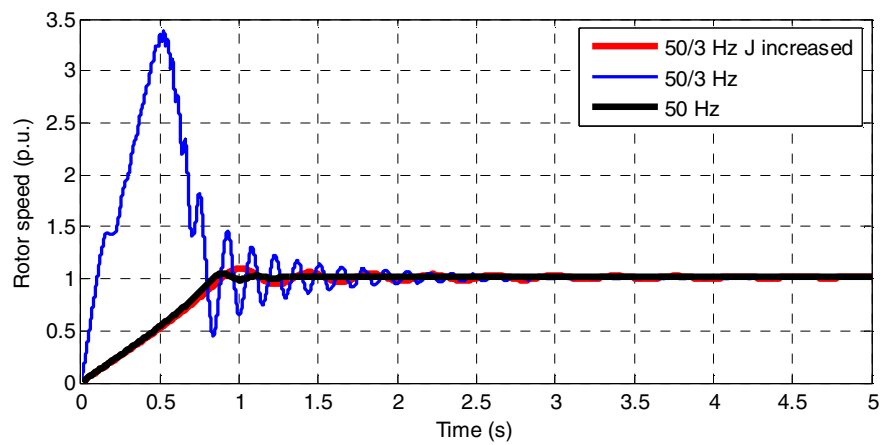

Fig. 8 Rotor speeds in both systems.

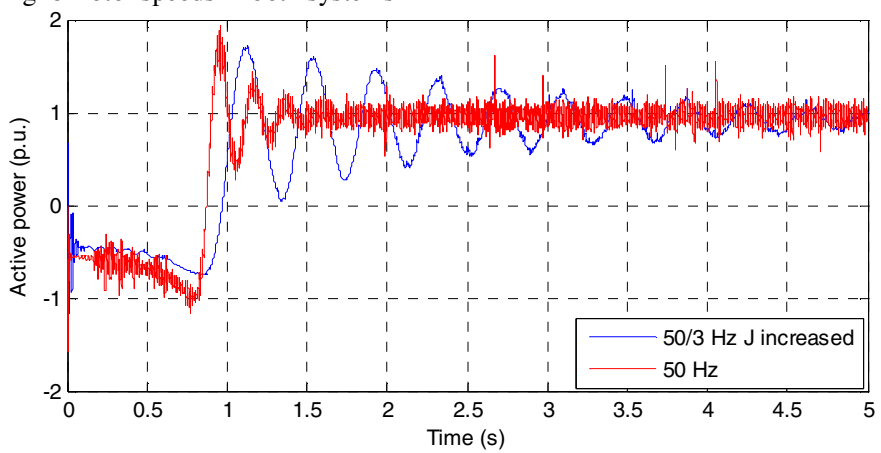

Fig. 9 Active power outputs in both systems.

The oscillations of the rotor speed, the active power and the reactive power during the dynamic operation have the same eigenfrequency, indicating they are induced by the same cause underneath. In the shown simulation, the input mechanical torque to the generator is kept constant. Hence, according to the Eq. 5, the observed oscillation is primarily due to the varying electromagnetic torque. In $[15,16]$, the oscillation of the electromagnetic torque is related to the variations of the magnitude and direction of the stator and rotor flux-linkage vectors. Increasing the rotor winding resistance by trial can damp the oscillation and improve the performance of the generator as shown in Fig. 10 and Fig. 11. Further research is underway to investigate fundamental reasons behind the oscillation phenomenon and propose the solutions for better damping. In the following studies, the generator model with larger inertia $(J)$ and winding resistance, for better damping properties, will be used to investigate the behaviours of the offshore wind turbines integration at different frequency regimes. The grid is modelled as an infinite bus in Fig. 7. Three cases are considered to investigate the compensation and dynamic behaviour in different scenarios. Again, the purpose of the simulation is to analyse and identify the needed redesign for the wind turbine in the $50 / 3 \mathrm{~Hz}$ system, given that the generator has the same nominal power. Notice that the synchronous speed in the LFAC system is only $1 / 3$ of the conventional AC system. Therefore, this, in reality, should lead to different design of the generators for optimal operational performance e.g. the efficiency according to the frequency, which will be investigated in our future work.

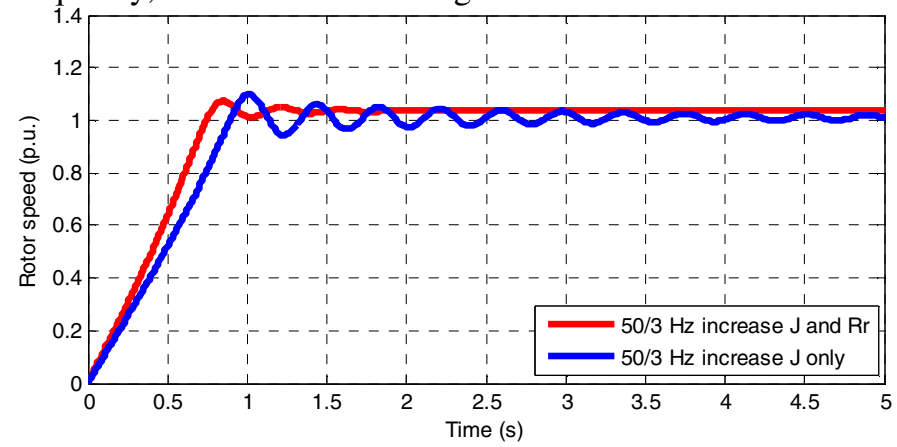

Fig. 10 Active power outputs in $50 / 3 \mathrm{~Hz}$ system.

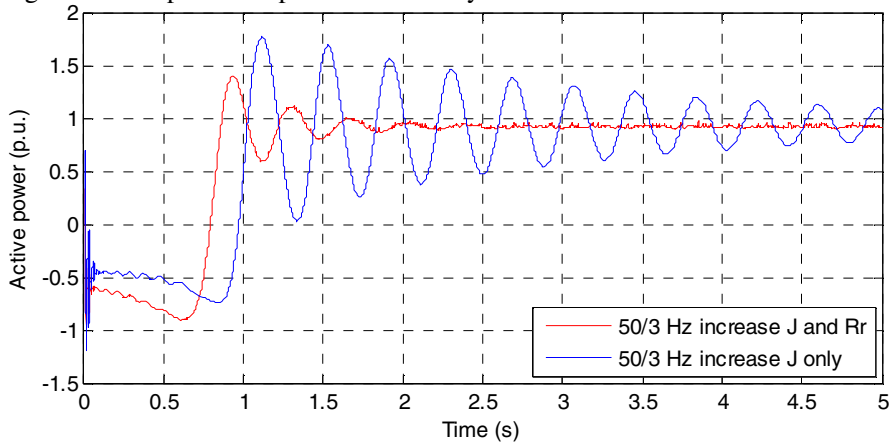

Fig. 11 Rotor speeds in 50/3 Hz system.

Case 1: The steady state simulation that to investigate the difference of capacitor compensation.

The reactive power compensation can be estimated by:

$$
Q=U^{2} / X_{m}
$$

where the magnetizing excitation reactive power for the generator $Q$ is provided by the capacitor bank. It can be estimated by neglecting the stator impedance. $U$ is the terminal voltage of the generator and the magnetizing reactance is denoted by $X_{m}$ that gives the most significant reactance of the generator to be compensated; all resistors are neglected. Hence, the required capacitance $(C)$ can be expressed by:

$$
C=1 /\left(4 \pi^{2} f^{2} L_{m}\right)
$$

where $L_{m}$ is the magnetizing inductance. Therefore, the reactive power needed in 50/3 $\mathrm{Hz}$ system should be 3 times of the $50 \mathrm{~Hz}$ system and the capacitance in $50 / 3 \mathrm{~Hz}$ system should be 9 times of the $50 \mathrm{~Hz}$ system. In this estimation, the grid impedance is not taken into account. Actually, the capacitor bank not only compensates the generator excitation, but also compensates the inductive grid. Therefore, if lowering down the frequency, the inductive impedance of the whole grid should be reduced, which indicates the required 
capacitance in the $50 / 3 \mathrm{~Hz}$ system should be lower than 9 times of the $50 \mathrm{~Hz}$ system. The accurate value of the required capacitance depends on the grid impedance.

Fig. 12 and Fig. 13 show the active power and the reactive power of the generator in each system from the starting up to the steady-state. In both cases, compensating the reactive power to ensure the P.F. $=1$ on the bus B2 to fulfill the common grid integration requirements for the wind turbine. In the steady state, the active power output in both systems on Bus B2 is 1 p.u., whilst the reactive power consumption is zero by setting a suitable value of the capacitance of the capacitor bank. The capacitor bank in $50 \mathrm{~Hz}$ provides 0.7 MVar reactive power whilst it is 1.68 MVar in $50 / 3 \mathrm{~Hz}$ system instead of the three times value 2.1 MVar calculated by Eq. 6 . Because the $\mathrm{X} / \mathrm{R}$ ratio of the inductive grid in the 50/3 system is only $1 / 3$ of the $50 \mathrm{~Hz}$ system due to the reduced frequency that reduces the inductive reactance of the whole grid.

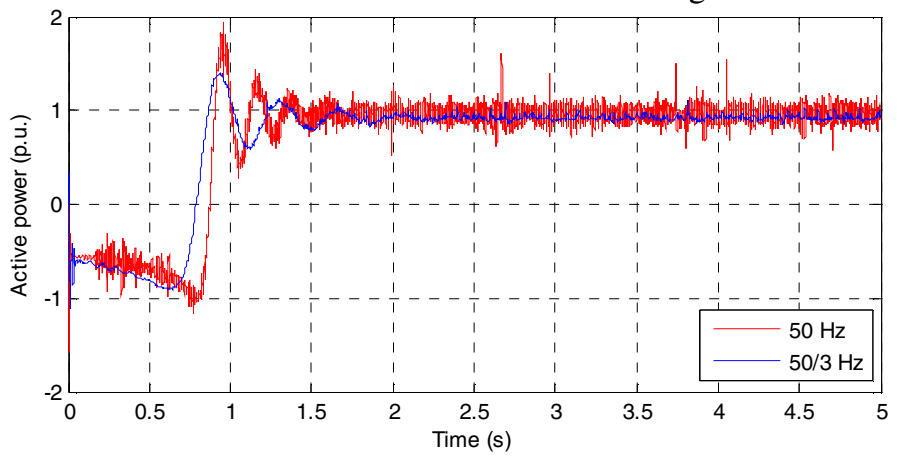

Fig. 12. Three-phase active power output on B2 of both systems.

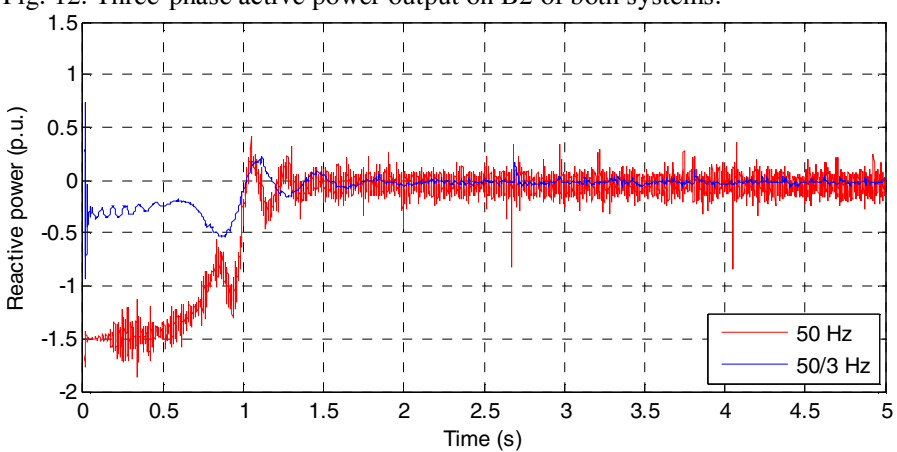

Fig. 13. Three-phase reactive power output on B2 of both systems.

Case 2: The torque change simulation that is to investigate the influence at variable wind speed when lowering down the grid frequency.

Rapid changes of the mechanical torque can be seen due to the wind speed variation. In this study, the torque changes at 3 sec. from 1 p.u. to 0.2 p.u. As Fig. 14 to Fig. 16 exhibits, the wind turbine in the LFAC system works well. The reactive power in both systems after $3 \mathrm{sec}$. is higher than zero, which means the capacitor bank produces more reactive power than required, as shown in Fig. 15. This is because the capacitor bank in this model is without any switching control. When the active power is reduced due to the lower wind speed, the reactive power compensation should be reduced accordingly.

Case 3: The short-circuit simulation that to investigate the influence during the faults when lowering the grid frequency.

A $100 \mathrm{~ms}$ three-phase short-circuit fault is introduced at the $3 \mathrm{sec}$, as given in Fig. 17 to Fig. 20. The voltage in both systems recovers with the support of the stiff grid after the fault is cleared. But the $50 \mathrm{~Hz}$ system recovers faster than the $50 / 3 \mathrm{~Hz}$ system, which is explained in terms of Eq. 5. The mechanical torque is constant $\left(T_{m}\right)$ during the fault, and the electromagnetic torque $\left(T_{e}\right)$ has an upward transient when the fault occurs due to the short-circuit transient of current at the fault's beginning, and then turns to zero. Finally, the system recovers when the fault is cleared. As the whole inductive reactance is much lower in the LFAC system, when the fault occurs, the generator delivers a big amount of power to the grid due to the big short-circuit current, as shown in Fig. 19. Hence, the rotor speed drops significantly as the fault occurs and then increases due to the zero of $T_{e}$.

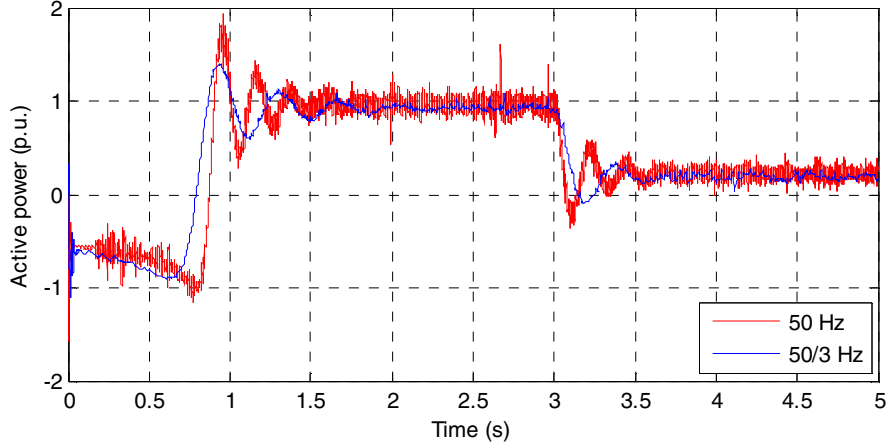

Fig. 14. The active power output when the torque changes from 1p.u. to 0.2 p.u.

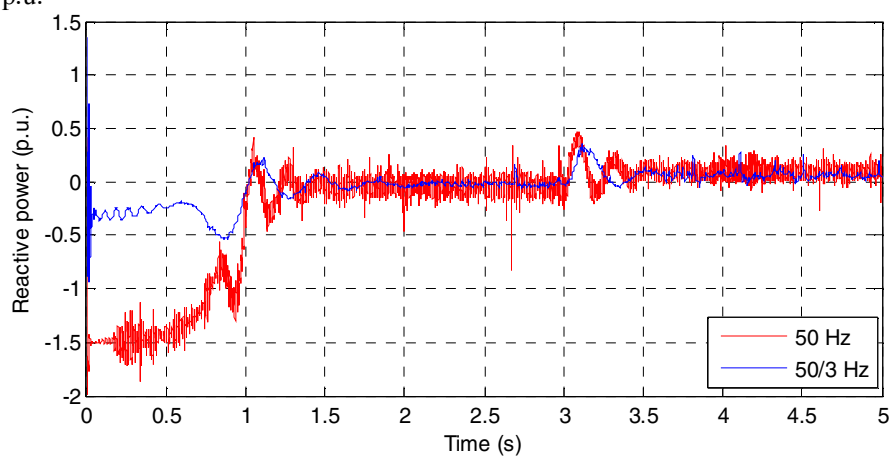

Fig. 15. The reactive power output when the torque changes from 1 p.u. to 0.2 p.u.

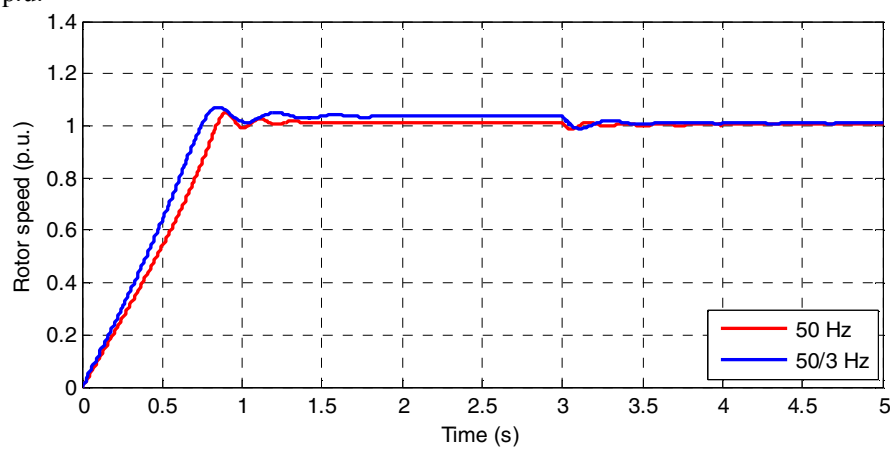

Fig. 16. The rotor speed when the torque changes from 1p.u. to 0.2 p.u.

In summary, the fixed-speed wind turbine can work in the LFAC system without difficulty. Some components should be redesigned, such as the generator for getting better performance, and the gear ratio is to be adjusted to the low frequency operation regime. For extracting the same amount of power by wind turbines as from the $50 \mathrm{~Hz}$ systems, a low gear ratio is proposed in LFAC systems. Modifying the inertia of the rotating mass and damping the oscillation of the flux for better performance could be the future work. Moreover, the 
problem of the fixed speed wind turbines in LFAC system is short-circuit current during the fault can be present, when comparing to the conventional $50 \mathrm{~Hz}$ systems. Reduction of such current transients in the LFAC systems is away the tasks to be solved.

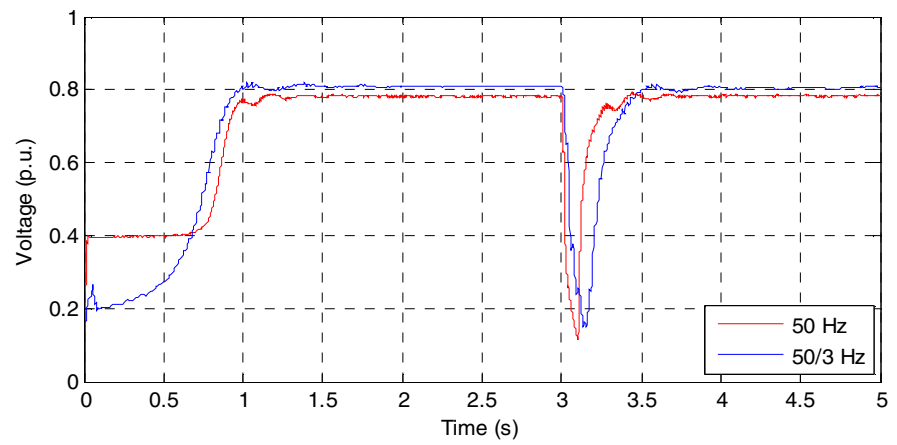

Fig. 17. The voltage during the fault.

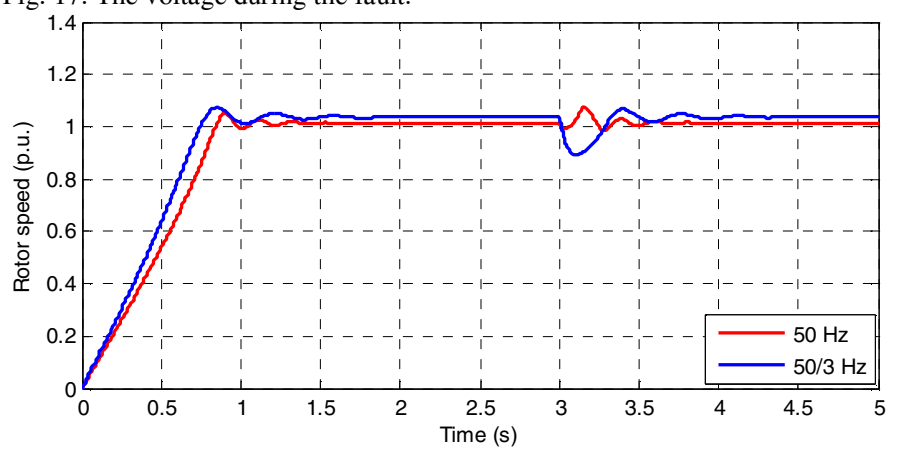

Fig. 18. The rotor speed during the fault.

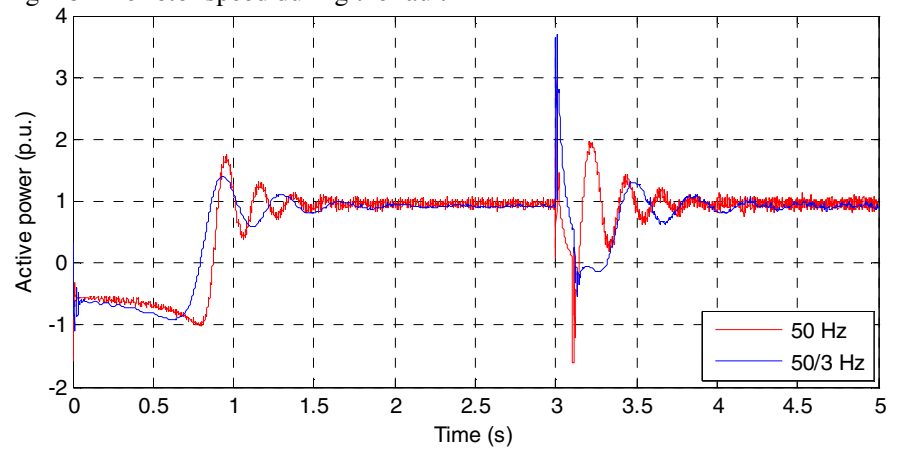

Fig. 19. The active power output during the fault.

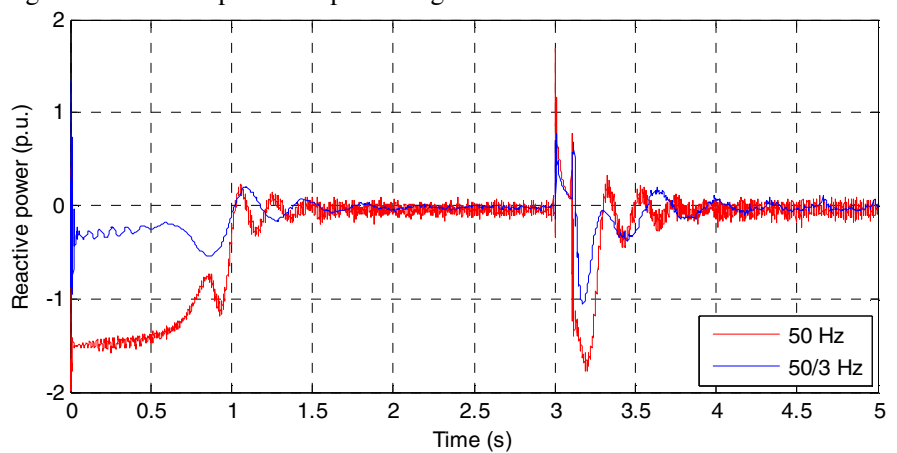

Fig. 20. The reactive power output during the fault.

\section{Cycloconverter simulation}

The cycloconverter, as shown in Fig. 2, connects the $50 \mathrm{~Hz}$ system to the $50 / 3 \mathrm{~Hz}$ system by frequency conversion. The simulation results, as shown in Fig. 21 and Fig. 22, indicates the harmonics problem along with the setting. The THD is $29.36 \%$ and the main harmonics are low order harmonics at $3^{\text {rd }}$, $5^{\text {th }}$ and $7^{\text {th }}$ orders where the base frequency is $50 / 3 \mathrm{~Hz}$. A filter system is hence needed to improve the power quality.

\section{CONCLUSION}

This paper proposes the LFAC system as a new and alternative solution to the conventional HVAC and HVDC systems which are so far deemed as the only solution for large offshore wind farms connection. With the cycloconverter that converts the $50 \mathrm{~Hz}$ to the lower frequency, for instance 50/3 $\mathrm{Hz}$, the transmission capability is greatly improved. A rough economic comparison with the conventional AC connection and the HVDC connection shows that the LFAC is competitive for short and intermediate, e.g. from 30 to $150 \mathrm{~km}$, transmission distances. The preliminary study based on the modelling and simulation of the LFAC system has been conducted. The results show the LAFC transmission capability is much greater than the conventional AC system, with improved voltage stability. When applied for grid integration of the fixed-speed wind turbine based wind farm, the LFAC system shows its limitations of increased oscillation and short circuit current. This indicates that the need to redesign the fixed speed wind turbine system such as the gear ratio, windings and inertia to best fit the LFAC system for optimal efficiency and operational performances would be necessary. An additional arrangement for better damping must also be proposed. Furthermore, the FFT analysis shows the cycloconverter can introduce increased amount of low order harmonics that needs to be filtered. Our future work will focus on further development of the LFAC system for wind power grid connection to improve overall system performance, by e.g. optimal filter design to reduce the harmonics, the detailed wind turbine (fixed speed) redesign to best fit the LFAC system operation, and considering other types of wind turbines.

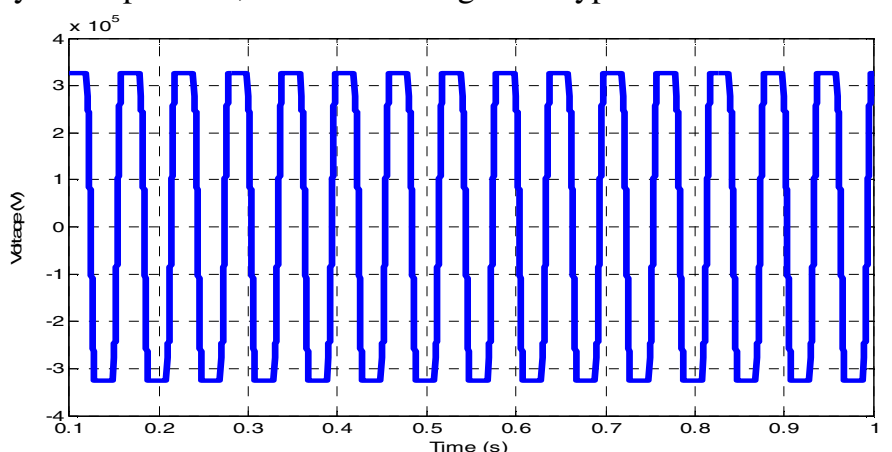

Fig. 21. The voltage output of single phase at no-load condition

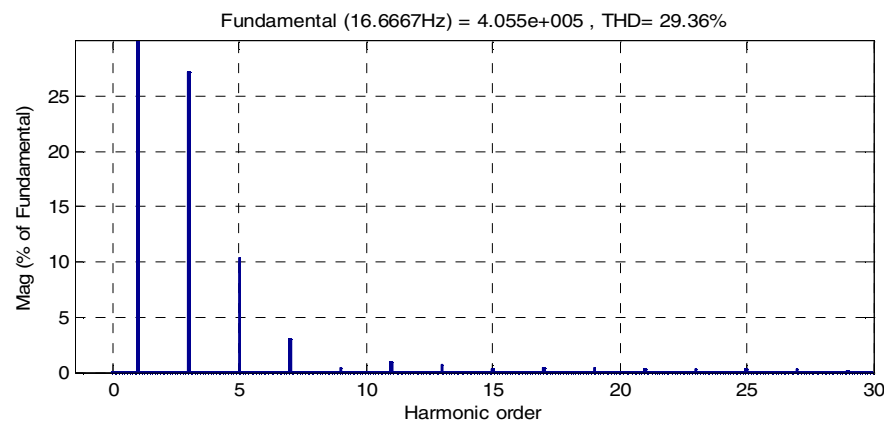

Fig. 22. The FFT analysis on the output voltage of the cycloconverter 


\section{REFERENCE}

[1] Ervin Spahić and Gerd Balzer, "Offshore Wind Farms - VSC-based HVDC Connection”, Power Tech 2005 IEEE Russia, Page 1-6.

[2] Elsam A/S, "Horns Ref Offshore Wind Farm, the world's largest offshore wind energy project", http://www.hornsrev.dk

[3] "HVDC transmission for lower investment cost", http://www.abb.com/cawp/GAD02181/C1256D71001E0037C12568320 064F435.aspx

[4] Ervin Spahić and Gerd Balzer," Impact of the VSC HVDC Connection of Large Offshore Wind Farms on Power System Stability and Control", 2007IEEE Lausanne, Volume, Issue, 1-5, 2007, Page 207-212.

[5] Anna-Karin Skytt, Per Holmberg, Lars-Erik Juhlin, "HVDC Light for connection of wind farms", Second International Workshop on Transmission Networks for Offshore Wind Farm, Royal Institute of Technology, Stockholm, Sweden, March 29-30, 2001.

[6] Stefan Lundberg, "Evaluation of Wind Farm Layouts", Chalmers University of Technology.

[7] Sally D. Wright, PE, Anthony L. Rogers, James F. Manwell, Anthony Ellis, "Transmission operation for offshore wind farms in the united states", Renewable Energy Research Lab.

[8] Moore, G.F. "Electric Cables Handbook ( $3^{\text {rd }}$ Edition)", Blackwell Publishing, Chapter 39

[9] F.N.Lim, R.J.Fleming, "Space Charge Accumulation in Power Cable insulation", IEEE Transactions on Volume 6, issue 3, June 1999 Page:273 -281

[10] Funaki. T and Matsuura. K, "Basic concept of Low Frequency AC transmission system", International Conference on Electrical Engineering (ICEE99), Vol. II, pp.17-20, 16-18 Aug, Hong Kong, 1999.

[11] Funaki. T, Matsuura, K. "Feasibility of the Low Frequency AC transmission", Power Engineering Society Winter Meeting, 2000. IEEE Volume 4, 23-27 Jan. 2000 Page: 2693-2698

[12] Wang Xifan; Cao Chengjun; Zhou Zhichao, "Experiment on Fractional Frequency Transmission System", Power Systems. IEEE Transactions on Volume 21, issue 1, Feb. 2006 Page: 372-377

[13] Miller N.W., Clark K., Piwko R.J., Larsen E.V., "Variable frequency transformer: Application for secure inter-regional power exchange", PowerGen Middle East 2006, Abu-Dhabi, Jan.2006, 10 pages.

[14] Prabha Kundur, "Power System Stability and Control", Chapter 11, Page 654 to Page 663

[15] Alakula, M.; Peterson, B.; Valis, J. "Damping of oscillations in induction machines", Power Electronics Specialists Conference, 1992. PESC ' 92 Record, $23^{\text {rd }}$ Annual IEEE, 29 June-3 July 1992 Page 133-38 vol.1

[16] Zhang, J.; Rahman, M.F.; Tang, L. "Modified direct torque controlled induction generator with space vector modulation for integrated starter alternator", Power Electronics and Motion Control Conference, 2004. The $4^{\text {th }}$ international. Vol 1, Issue, 14-16 Aug.2004 Page: 405-408 Vol.1

\section{BIOGRAPHIES}

Nan Qin was born in Beijing, P.R.China, on December 12, 1983. He received B.Sc. in E.E. from the Beijing University of Technology. He is pursuing the M.Sc. in Wind Master at the Technical University of Denmark. He is interested in the wind power generation that concerning the power electronics, offshore wind farm connection and wind farm operation analysis.

Shi You received the B.Sc. in E.E. from Harbin Institute of Technology, China, and the M.Sc. in E.E. from Chalmers Institute of Technology, Sweden in 2004 and 2006, respectively. He is currently pursuing the $\mathrm{PhD}$. degree in Electrical Engineering at the Technical University of Denmark. His main fields of interest are renewable energy and electricity market.

Zhao Xu (S'00, M'06) received $\mathrm{PhD}$. in electrical engineering from University of Queensland in 2006. Form 2006-2008, he was an Assistant Professor at Centre for Electric Technology, Technical University of Denmark Since 2009, he is an Associate Professor at the same institute. His research interests include demand side, grid integration of wind power, electricity market planning and management, $\mathrm{AI}$ applications.

Vladislav Akhmatov received $\mathrm{PhD}$. from the Technical University of Denmark in 2003. From 1998 to 2003 he was with the Danish distribution power company NESA, now a part of Dong Energy, from 2003 to 2007 with the Danish TSO, Energinet.dk, from 2007 to 2008 with Siemens Wind Power. $\mathrm{He}$ is now a Professor with special responsibilities in Electric Power Systems at the Technical University of Denmark. The main interests are power system modelling and stability, wind power integration and wind turbine modelling. 